\title{
Stimulation of $\beta$-adrenoceptors with isoprenaline inhibits small intestinal activity fronts and induces a postprandial-like motility pattern in humans
}

\author{
M Thollander, T H Svensson, P M Hellström
}

\begin{abstract}
Aims-To investigate the effects of $\beta$ adrenoceptor stimulation, using the agonist isoprenaline and the antagonist propranolol, on migrating motor complexes in the upper intestine of 16 healthy human volunteers.
\end{abstract}

Methods-Fasting motility was monitored using a tube with water perfused side holes connected to a pneumohydraulic system. Continuous eight hour recordings were obtained from each volunteer after a 12 hour fasting period. In all experiments, saline was given as control for the first four hour period and $\beta$-adrenergic agents for the next four hours. In separate control studies, saline was given for the whole eight hour period.

Results-Isoprenaline $(2.5 \mu \mathrm{g} / \mathrm{kg} / \mathrm{min}) \mathrm{re}-$ duced the number of activity fronts (phase III) of migrating motor complexes from 3 $(2-4)$ in controls to $1(0-2)$ during isoprenaline infusion $(p<0 \cdot 01)$. Also, phase II-like activity replaced the regular motility pattern $(p<0 \cdot 01)$. By contrast, propranolol $(25 \mu \mathrm{g} / \mathrm{kg} / \mathrm{min})$ did not induce any significant changes in phase III compared with controls. Saline alone had no effect on motor activity.

Conclusions-Isoprenaline inhibited activity fronts in the human proximal small intestine and induced a postprandial-like motility pattern, whereas propranolol did not affect motor patterns. Stimulation of $\beta$-adrenoceptors is of importance in the control of motor activity of the human small intestine, especially under stressful conditions with high adrenergic activity.

(Gut 1997; 40: 376-380)

Keywords: isoprenaline, propranolol, migrating motor complex, small intestine.

Gastroenterology,

Department of

Medicine, Karolinska

Hospital, Stockholm, Sweden

M Thollander

P M Hellström

Department of Physiology and Pharmacology, Karolinska Institute, Stockholm, Sweden $\mathrm{T} \mathrm{H}$ Svensson

Correspondence to: Dr Per $M$ Hellström, Section of Gastroenterology, Department of Medicine, Karolinska Hospital, S-171 76
Sweden.

Accepted for publication 20 September 1996 stimulation of $\beta_{3}$-adrenoceptors inhibits myoelectric activity of the small intestine. ${ }^{8}$

In humans, $\beta$-adrenoceptor stimulation reduces oesophageal, ${ }^{9}$ antral, ${ }^{9}$ and duodenal mo- $\vec{\circ}$ tility. ${ }^{10}$ By contrast, $\beta$-adrenoceptor inhibition with propranolol was recently found to enhance $\vec{\omega}$ motility of the oesophagus, ${ }^{11}$ promote gastric 0 emptying, ${ }^{12}$ increase colonic intraluminal pressure, ${ }^{13}$ and shorten the period of postoperative $\stackrel{\overrightarrow{0}}{\mathrm{c}}$ adynamic ileus after bowel surgery. ${ }^{14} 15$

As an extension of our previous studies on $\partial$ effects of $\beta$-adrenergic compounds on myo- 0 electric activity in rats, ${ }^{8}$ we evaluated the effects ${ }_{-}$ of isoprenaline and propranolol on fasting duo- $z$ denojejunal motor activity in healthy volun- $\frac{0}{\circ}$ teers. To our knowledge, no studies have yet $\stackrel{\supset}{\supset}$ been performed to investigate the effects of $\vec{\theta}$ $\beta$-adrenergic agents on the migrating motor. complex in the small intestine of humans. Thus the purpose of this study was to explore the potential role of $\beta$-adrenoceptors in the control of fasting motility in the human small bowel.

\section{Methods}

\section{Volunteers}

Sixteen healthy male volunteers aged $21-550$ (mean 32.0 ) years participated in the study. None reported symptoms or history of gastro- 3 intestinal disease and none was on medication. Seven of the subjects also participated in a 3 control study in which only saline was given. 0 The experimental protocol was approved by the local ethics committee at the Karolinska Hospital. Informed consent was obtained from all subjects.

\section{Intestinal motility recordings}

Motility of the proximal small intestine wase monitored by means of a multichannel poly- $\overparen{\Phi}$ vinylchloride tube (William Cook, Bjaeverskov, Denmark). The tube was $250 \mathrm{~cm}$ in length and 0 $4.7 \mathrm{~mm}$ in outer diameter and had seven $\frac{\vec{D}}{\mathrm{D}}$ channels $0.7 \mathrm{~mm}$ in width, ending as side holes $\stackrel{?}{\Phi}$ at different levels. Four side holes, $10 \mathrm{~cm}$ apart, $\varrho$ were used in this study. The tube assembly was passed through a nostril. Fluoroscopy was used 8 to position the two proximal side holes in the? descending (D1) and horizontal (D2) parts of the duodenum, and the distal two at the angle? of Treitz (T) and in the jejunum (J). Each channel was continuously perfused with degassed water from a low compliance pneumohydraulic system (Arndorfer Medical Specialities, Greendale, WI, USA) at a rate of $0.4 \mathrm{ml} /$ min. The channels were connected to external pressure transducers (PDCR 75, Druck Ltd, 
Leicestershire, UK). Recordings were made on a multichannel ink jet recorder (Mingograph 81, Elema-Schönander, Stockholm, Sweden). The velocity of the pressure rise on sudden occlusion of the recording system was $200 \mathrm{~mm}$ $\mathrm{Hg} / \mathrm{s}$ in each channel.

\section{Study design}

The volunteers fasted overnight before the experiment. Recordings were started at $800-830$ am and continued for eight hours. Volunteers were in recumbent position throughout the experiment. Each experiment consisted of two consecutive motility registration periods of four hours duration. A continuous infusion of saline was given during the first four hour control period and either saline, isoprenaline, or propranolol during the next four hours.

In the control group, comprising seven subjects, saline was given for two consecutive four hour periods. Isoprenaline $(2.5 \mu \mathrm{g} / \mathrm{kg} / \mathrm{min})$ was given to nine subjects and propranolol (25 $\mu \mathrm{g} / \mathrm{kg} / \mathrm{min}$ ) was given to seven volunteers.

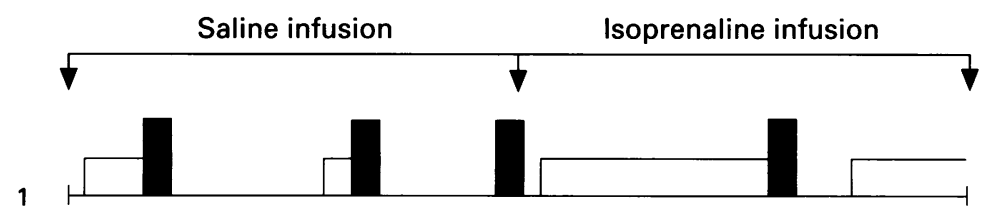

2

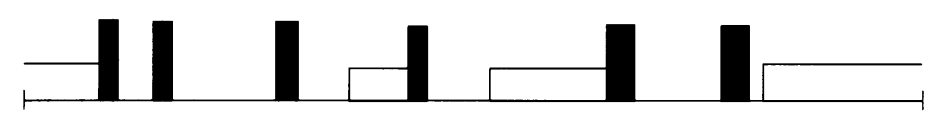

3
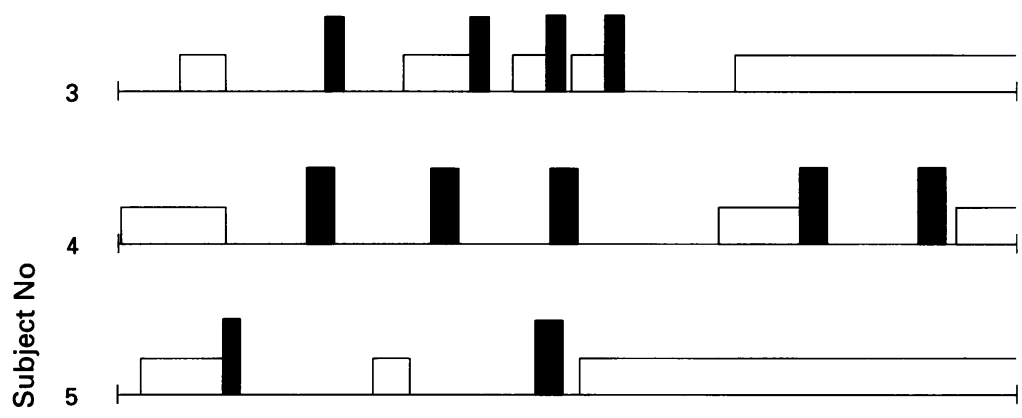

6
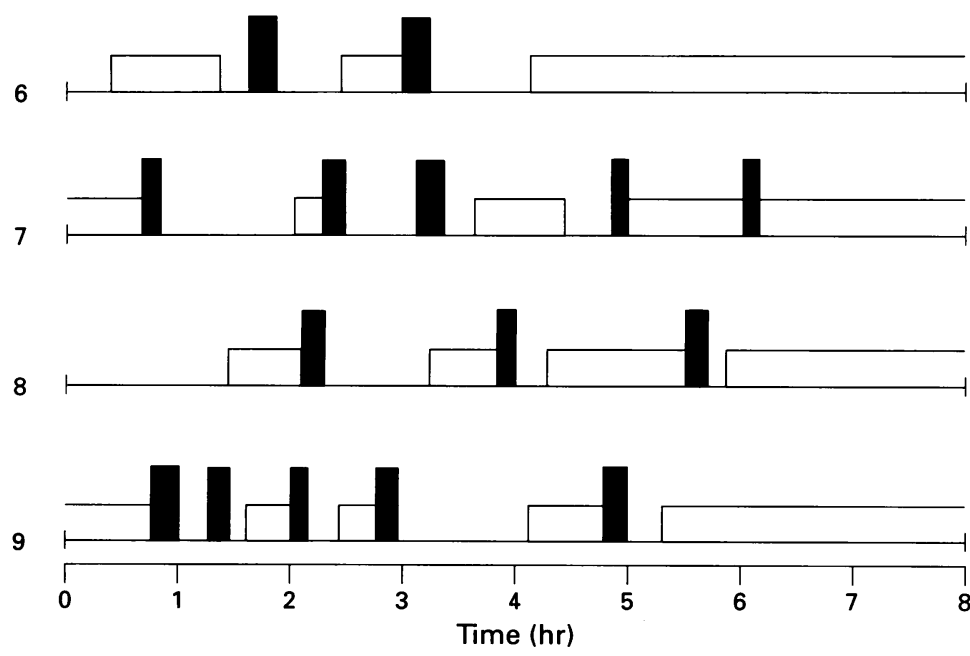

Figure 1: Fasting motility of the small intestine in nine volunteers. Baseline represents phase I, $\square$ phase II, and phase III (activity front) of migrating motor complex. Arrows indicate start and finish of continuous saline and isoprenaline $(2 \cdot 5 \mu \mathrm{g} / \mathrm{kg} / \mathrm{min})$ during two four hour periods.
Blood pressure and heart rate were registered 10 minutes before drug administration and every 10 minutes thereafter. Subjects were monitored for side effects throughout the study.

Drugs

These were saline solution $(9 \mathrm{mg} / \mathrm{ml} \mathrm{Nat-}$ riumklorid, Kabi Vitrum, Stockholm, Sweden), isoprenaline (Apoteksbolaget, Umeå, Sweden) and propranolol (Zeneca, Macclesfield, Cheshire, UK).

\section{Data analysis of migrating motor complex}

Recordings were inspected by two independent observers who agreed on the presence or absence of motor patterns. Migrating motor complexes were identified according to criteria of Vantrappen et $a l^{16}$ : (1) appearance of uninterrupted bursts of pressure waves with a frequency of 11-12 contractions per minute (phase III), (2) aboral migration of phase III activity passing at least the distal two registration points, and (3) a period of complete quiescence after phase III activity. Phase III of migrating motor complexes (activity front) was defined as the presence of uninterrupted phasic pressure changes for at least two minutes at the maximal frequency for that locus. The duration of phase III at each locus was measured from onset of regular contractions to quiescence. The propagation velocity of phase III was calculated by dividing the traversed distance from onset of phase III by the time interval from one registration point to the next. Phase II was defined as having $\geq 1$ phasic contractions per minute, whereas phase I was defined as silence.

\section{Statistics}

Results are expressed as median values and range. Statistical comparisons with controls were made with Wilcoxon's signed rank test; $\mathrm{p}<0.05$ was considered significant.

\section{Results}

In every subject, each phase III of migrating motor complexes was observed migrating over all four intestinal recording sites.

In control studies with saline, the number of phase III migrating motor complexes recorded during the first four hour infusion period were $2(2-4)$, compared with $2(1-3)$ during the subsequent four hour recording period. Also, no changes were found for duration, contraction frequency, and propagation velocity of phase III between the two four hour periods.

\section{Effects of $\beta$-adrenoceptor stimulation on migrating} motor complex pattern

Isoprenaline decreased the number of phase III migrating motor complexes from $3(2-4)$ in the control period to $1(0-2)$ during isoprenaline infusion $(p<0 \cdot 01 ; \mathrm{Fig} 1)$. There were no changes in the duration, contraction frequency, 
Characteristics of phase III of the migrating motor complexes in human volunteers during a four hour infusion of saline, followed by a four hour infusion of either isoprenaline $(2 \cdot 5 \mu \mathrm{g} / \mathrm{kg} / \mathrm{min} ; \mathrm{n=9})$, or propranolol $(25 \mu \mathrm{g} / \mathrm{kg} / \mathrm{min} ; \mathrm{n}=7)$

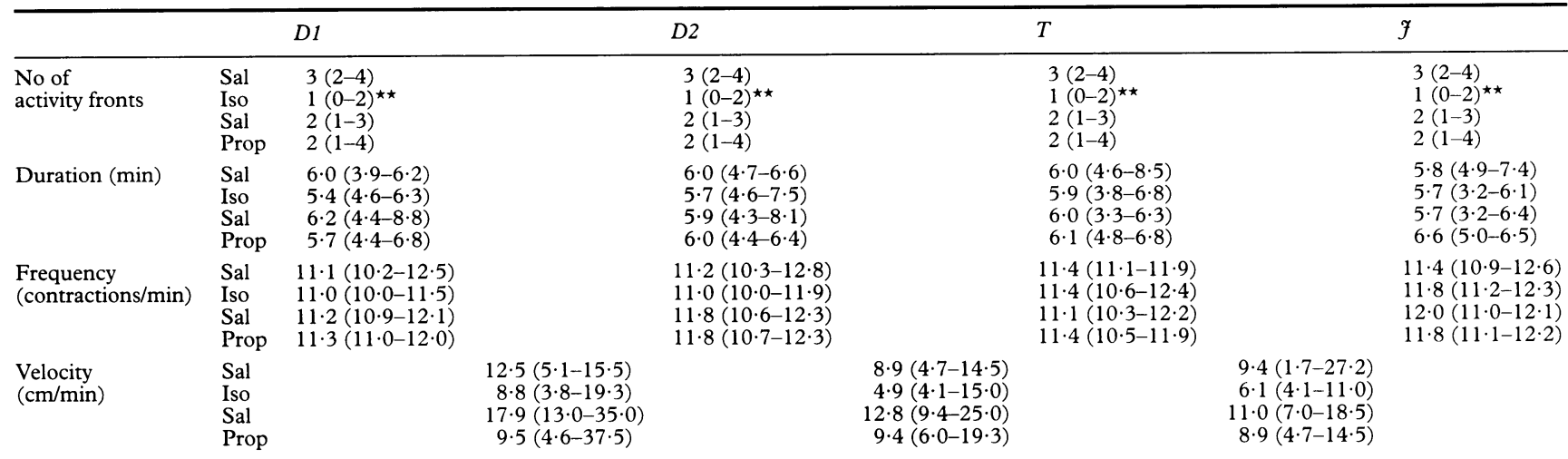

Results are expressed as median (range). D1 and D2 indicate positions of the side holes of the tube located 20 and $10 \mathrm{~cm}$ proximal to the angle of Treitz respectively. T and J indicate side holes at ligament of Treitz and $10 \mathrm{~cm}$ distal to the angle respectively. Sal=saline; Iso $=i$ isoprenaline; Prop=propranolol. ${ }^{\star \star} \mathrm{p}<0 \cdot 01$.

and propagation velocity of phase III of migrating motor complexes compared with controls (Table).While suppressing the migrating motor complex pattern, isoprenaline induced phase II-like activity throughout the four hour infusion period. An increase in fraction of time occupied by this phase II-like activity was found $(p<0 \cdot 01)$, whereas decreases in phase I and III activity were registered (each $\mathrm{p}<0.01$; Fig 2 ).

Isoprenaline increased systolic blood pressure from $120(105-130)$ to $155(130-165)$
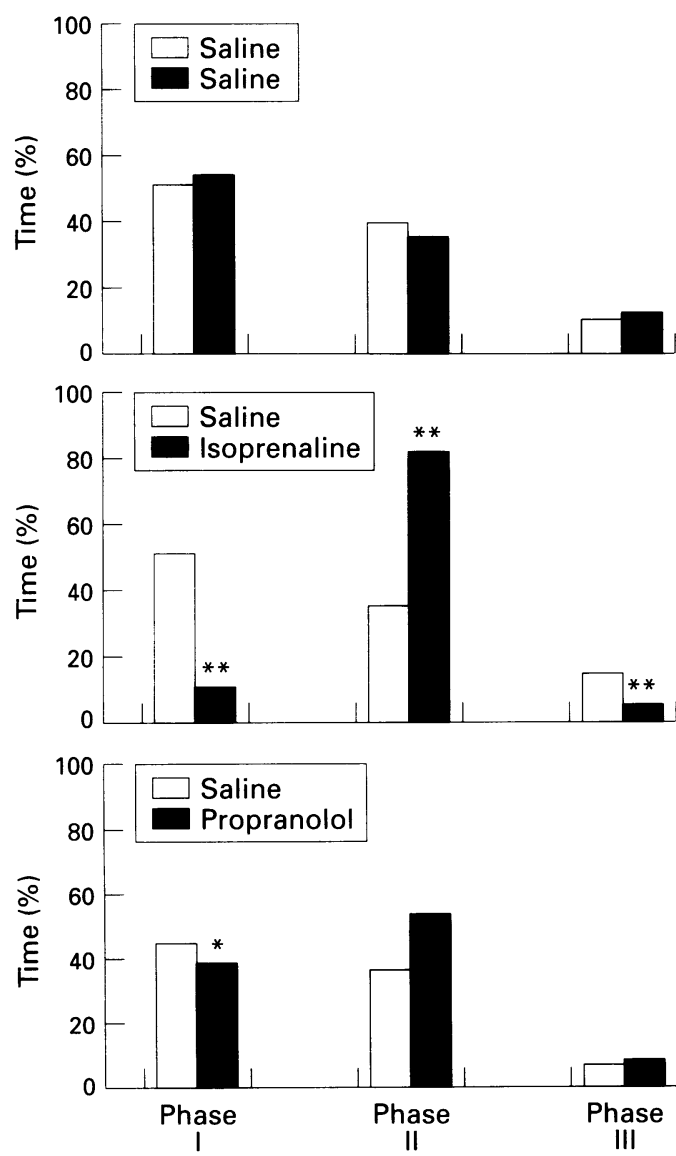

Figure 2: Fraction of time occupied by phases I, II, and III. $\square$ First four hour period when only saline was given;

second four hour period when (top panel) saline, (middle panel) isoprenaline, (bottom panel) propranolol was given. Fraction of the three phases is expressed as percentage of the respective four hour period. Values are given as medians. ${ }^{\star} p<0.05 ;{ }^{\star \star} p<0.01$. $\mathrm{mm} \mathrm{Hg}(\mathrm{p}<0.01)$, whereas the diastolic

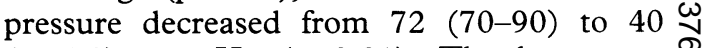
$(26-70) \mathrm{mm} \mathrm{Hg}(\mathrm{p}<0.01)$. The heart rate increased from $60(40-72)$ during the control period to $112(100-135)$ beats/min during $\vec{z}$ isoprenaline infusion $(\mathrm{p}<0.01)$.

Effects of $\beta$-adrenoceptor inhibition on migrating motor complex pattern

With propranolol at a dose of $25 \mu \mathrm{g} / \mathrm{kg} / \mathrm{min}$, the frequency of phase III did not change signifi-

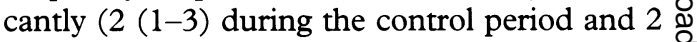
(1-4) during propranolol infusion; Fig 3). No $\frac{\mathbb{Q}}{2}$ changes in duration, contraction frequency, or $\vec{F}$ propagation velocity of phase III between the $\frac{0}{3}$ two four hour periods were found (Table).

The time fraction of the different phases of migrating motor complexes during propranolol infusion did not show any significant differences compared with the control period except $\frac{5}{3}$ for phase I ( $p<0 \cdot 05$; Fig 2$)$.

Propranolol decreased systolic blood pressure $\frac{8}{3}$ from $120(110-140)$ to $110(100-130) \mathrm{mm} \mathrm{Hg}$ $(\mathrm{p}<0.05)$, whereas the diastolic pressure increased from $69(55-80)$ to $80(60-85) \mathrm{mm} \mathrm{Hg}$ 응 $(\mathrm{p}<0.05)$. The heart rate decreased from 65 (60-79) during the control period to $51(48-72) \Omega$ beats/min during propranolol infusion $(\mathrm{p}<0.05)$. N

Discussion

Inhibitory sympathetic influence on gut $\frac{\text { }}{\Phi}$ motility was described as early as 1899 by $\stackrel{\mathscr{?}}{+}$ Bayliss and Starling in their studies on the $\frac{T}{\circ}$ small intestine of dogs. ${ }^{17}$ Although the signifi- $\frac{\vec{D}}{\mathbb{D}}$ cance of this influence and its interaction with $\stackrel{\square}{9}$ the parasympathetic nervous system was $\stackrel{\mathbb{Q}}{\varrho}$ initially unclear, it soon became evident that extrinsic noradrenergic nerves play an import- 8 ant part in the regulation of gut motility.

The present study shows that non-selective $\beta$-adrenoceptor stimulation employing the agonist isoprenaline was associated with a reduction in phase III and an increase in phase II-like activity in the proximal small intestine of humans, whereas non-selective $\beta$-adrenoceptor inhibition using propranolol did not affect the basal migrating motor complex pattern. These findings are in accordance with several animal 

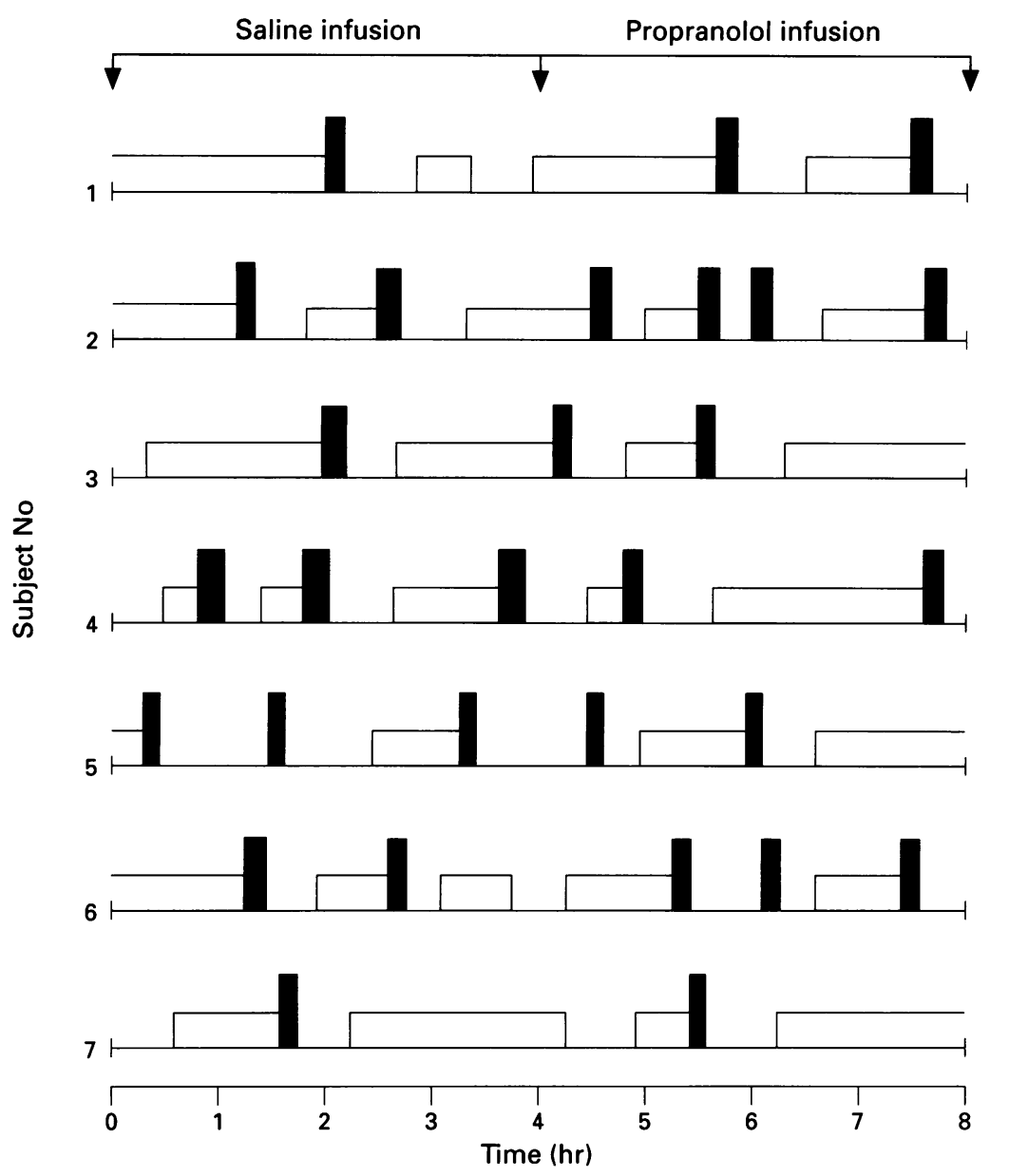

Figure 3: Fasting motility of the small intestine in seven volunteers. Baseline represents phase I, $\square$ phase II, and phase III (activity front) of migrating motor complex. Arrows indicate start and finish of continuous saline and propranolol $(25 \mu \mathrm{g} / \mathrm{kg} / \mathrm{min})$ during two four hour periods. stimulation. In the rabbit ileum, inhibition of sympathetically induced loss of contractility is abolished by the $\beta_{1}$-adrenoceptor antagonist atenolol ( $75 \%)$ as well as by the $\beta_{2}$-adrenoceptor antagonist butoxamine $(25 \%)$. This is in agreement with the above mentioned hypothesis of both $\beta_{1}$-adrenoceptor and $\beta_{2}$-adrenoceptor responsiveness in smooth muscle cells. ${ }^{28}$ In a recent study we showed that mainly $\beta_{2^{-}}$ adrenoceptor stimulation is important in the regulation of motility of the small intestine in rats by disrupting the regular migrating motor complexes pattern and inducing irregular spiking. ${ }^{8}$ In the same species, stimulation of $\beta_{1}$-adrenoceptors did not affect myoelectric activity. In addition, atypical $\beta$-adrenoceptors (for example, the $\beta_{3}$ subtype), which are distributed in the gastrointestinal tract ${ }^{29}{ }^{30}$ disrupt the regular migrating motor complexes, and induce quiescence in rats when given intravenously. ${ }^{8}$ The importance of $\beta_{3}$-adrenoceptor stimulation in the human gut is still of unknown biological relevance.

To date, few studies have investigated the effects of $\beta$-adrenergic compounds on motility of the small intestine in humans. In the study by McIntyre et al, ${ }^{10}$ carried out in the postprandial state, isoprenaline infusion delayed orocaecal and duodenocaecal transit compared with placebo. This effect is likely to be due to an effect on motor function as isoprenaline was reported to reduce the amplitude of postprandial antral contractions. ${ }^{10}$ Our present findings in fasted humans confirm that $\beta$-adrenoceptor stimulation in humans may influence motility of the small bowel by disrupting the regular migrating motor complex pattern. Our results and those of McIntyre et $a l^{10}$ may initially seem contradictory, as our results showed increased contractile activity that is, phase II-like activity - during the whole period of isoprenaline infusion. However, the occurrence of phase III decreased during isoprenaline infusion but no obvious effect was seen on the amplitude of duodenal or jejunal contractions. Taken together with the fact that phase III is the most important phase contributing to the propulsive capacity of the intestine, this may confirm its inhibitory action on motility expressed as decreased orocaecal and duodenocaecal transit, confirming the findings of McIntyre et al. ${ }^{10}$ Of note, the dose of isoprenaline used in their study was one order of magnitude lower than the one used in the present study to achieve an effect on the fasting motor pattern. The differences in doses used may reflect differences in sensitivity of the small intestine to $\beta$-adrenoceptor stimulation under different motor patterns, such as postprandial and fasting motility.

By contrast with isoprenaline, propranolol has been shown to accelerate orocaecal as well as duodenocaecal transit of both solid and liquid meals in humans. ${ }^{10}$ This effect is thought to be mediated by $\beta_{1}$-adrenoceptors as atenolol produces a similar degree of acceleration of transit as propranolol. Similar to the findings of McIntyre et $a l^{10}$ Morris et al ${ }^{11}$ found that isoprenaline reduced motor wave activity in humans, but propranolol had no consistent activity in the small intestine, ${ }^{25}{ }^{26}$ whereas propranolol, under in vitro conditions, does not affect spontaneous motility. ${ }^{27}$ However, propranolol abolished the inhibition of spontaneous motility induced by perivascular nerve stimulation, ${ }^{27}$ which indicates that this sympathetic effect is mediated through $\beta$-adrenoceptor 
motor effect. This is in accordance with results from a recent animal study, as well as with our present study, in which propranolol did not exert any consistent effect on fasting motor activity of the small intestine. These results may be explained by the fact that propranolol's effect on orocaecal transit time is not mainly due to an action on small intestine, but rather on gastric emptying and colonic motility (see introduction). Thus the paucity of effect of $\beta$-adrenoceptor inhibition in this study suggests little physiological role for $\beta$-adrenoceptor mechanisms in the regulation of small intestinal motility. However, the stimulatory effect of non-selective $\beta$-adrenoceptor agonists producing phase II-like activity by disrupting the migrating motor complexes pattern favours a role for $\beta$-adrenoceptor stimulation during sympathetic activation of the gut as seen in stress reactions. Evidence for such mechanisms has been presented by Valori et al. ${ }^{32}$ In their study in humans, different kinds of stressors produced irregular contractile activity in the proximal small intestine, simultaneously with reduced frequency of phase III activity. These findings are commensurate with our present data from experiments on the small intestine in rat, ${ }^{8}$ as well as the current study in humans. The effects of $\beta$-adrenoceptor activation in this study closely resemble the initiation of a motor pattern after feeding. Thus the findings may display drug induced conversion of fasted state into a postprandial motility pattern.

The present results do not discriminate between $\beta_{1}$-adrenoceptor and $\beta_{2}$-adrenoceptor stimulation in the control of upper small intestinal motility in humans. However, earlier animal studies by our group ${ }^{8}$ suggest that $\beta_{2}$-adrenoceptor stimulation preferentially induces irregular spiking activity and inhibits activity fronts similar to effects noted in humans. Further investigations to explore the relative importance of different subsets of adrenergic $\beta_{1}$-receptors and $\beta_{2}$-receptors for gut motility in humans are therefore needed.

Finally, as the dose of isoprenaline used in our study is within recommendations for clinical usage, central nervous effects of the drug would be minimal. In this study, no major side effects were noted by the subjects when isoprenaline or propranolol was given. The findings, therefore, indicate that $\beta$-adrenergic control of motor activity in human small intestine involves peripheral mechanisms. A possible clinical implication of these findings relates to the increasing use of pharmacological agents to ameloriate motility disorders of the gastrointestinal tract in humans.

This work was supported by the Swedish Medical Council (7916), Karolinska Institute, the Swedish Society of Medicine, the Swedish Society for Medical Research, Stiftelsen Sigurd och Elsa Goljes Minne, Stiftelsen Ruth och Richard Julins Fond, Stiftelsen Professor Nanna Svartz Fond, Åke Wibergs Stiftelse, and SmithKline Beecham

1 Ruwart MJ, Klepper MS, Rush BD. Clonidine delays smal intestinal transit in the rat. F Pharmacol Exp Ther 1980, 212: 487-90.

2 Fargeas MJ, Fioramonti J, Bueno L. Central $\alpha_{2}$-adrenergic control of small intestinal motility in rats. Gastroenterology 1986; 91: 1470-5.

3 Doherty NS, Hancock AA. Role of alpha-2 adrenergic receptors in the control of diarthea and intestinal motility. f Pharmacol Exp Ther 1983; 225: 269-74.
4 Thollander M, Hellström PM, Svensson TH. Suppression of small intestinal motility and morphine withdrawal diarrhoea by clonidine: peripheral site of action. Acto Physiol Scand 1989; 137: 385-92.

5 Schiller LR, Santa Ana CA, Morawski SG, Fordtran JS Studies of the antidiarrheal action of clonidine. Gastroenterology 1985; 89: 982-8.

6 Thollander M, Svensson TH, Hellström PM. Differential effects of $\alpha_{2}$-adrenoceptor agonists on migrating motor complexes in healthy volunteers: stimulation by clonidine and inhibition by oxymetazoline. Eur $\mathcal{f}$ Gastroenterol Hepatol 1993; 5: 731-7.

7 Thollander M, Hellström PM. Adrenergic inhibition of migrating myoelectric complex in the rat is preferentially exerted by $\alpha_{2}$-adrenoceptors. Acta Physiol Scand 1995; 153: 397-9.

8 Thollander M, Svensson TH, Hellström PM. $\beta-$ 的 Adrenoceptors regulate activity in the small intestine of $\overparen{D}$ Neurogastroenterol Motil 1996; 8: 143-51.

9 Lyrenäs E, Abrahamsson H. Beta adrenergic influence on oesophageal peristalsis in man. Gut 1986; $27: 260-6$.

10 McIntyre AS, Thompson DG, Day S, Burnham WR, $\vec{\circ}$ Walker E. Modulation of human upper intestinal nutrient $\vec{\overrightarrow{ }}$ transit by a beta adrenoceptor mediated pathway. Gut $\vec{\omega}$
1992; 33: 1062-70.

11 Zfass AM, Prince R, Allen FN. Inhibitory beta adrenergic $\widehat{C}$ receptors in the human distal esophagus. Am $\mathcal{F}$ Physiol 1970; 15: 303-10.

12 Tkaczewski W, Chojnacki J. Gastric emptying after adrenolytic agents in duodenal ulcer patients (abstract of $\omega$ the XI International Congress of Gastroenterology). $\omega$ Hepato-Gastroenterol 1980; 107 (suppl).

Hepato-Gastroenterol 1980; 107 (suppl).
13 Abrahamsson H, Lyrenäs E, Dotevall G. Effects of betaadrenoceptor blocking drugs on human sigmoid colonic motility. Dig Dis Sci 1983; 28: 590-4.

14 Hallerbäck B, Carlsen E, Carlsson K, et al. $\beta$-Adrenoceptor $\vec{Z}$ blockade in the treatment of postoperative adynamic ileus. Scand $\mathcal{f}$ Gastroenterol 1987; 22: 149-55.

15 Hallerbäck $B$, Ander $S$, Glise $H$. Effect of combined $\stackrel{\rho}{\supset}$ blockade of $\beta$-adrenoceptors and acetylcholinesterase in $\rightarrow$ the treatment of postoperative ileus after cholecystec- $\overrightarrow{0}$ tomy. Scand $\mathcal{F}$ Gastroenterol 1987; 22: $420-4$.

16 Vantrappen G, Janssens J, Hellemans J, Ghoos Y. The interdigestive motor complex of normal subjects and patients with bacterial overgrowth of the small intestine. $\mathcal{F}$ Clin Invest 1977; 59: 1158-66.

17 Bayliss WM, Starling EH. The movements and innervation of the small intestine. $₹$ Physiol (Lond) 1899; 24: 99-143.

18 Brikas P, Buéno L, Fioramonti J. Central and peripheral $\beta$-adrenergic influences on reticulo-rumen and upper-gut $\mathbb{D}$ myoelectrical activity in sheep. $\mathcal{F}$ Vet Pharmacol Therap $\vec{F}$ 1989; 12: 430-7.

19 Yanda R, Summers RW. Activity fronts in fed dogs: effects of a $\beta$-adrenergic agonist. Am $\mathcal{F}$ Physiol 1983; 245: G647-50.

20 Fontaine J, Grivegnee A, Reuse J. Adrenoceptors and regulation of intestinal tone in the isolated colon of the mouse. Br f Pharmacol 1984; 81: 231-43.

21 Ek BA, Bjellin LAC, Lundgren BT. $\beta$-adrenergic control of motility in the rat colon. I. Evidence for functional $\vec{\sigma}$ separation of the $\beta_{1}$ and $\beta_{2}$-adrenoceptor-mediated inhi- $\frac{\sigma}{3}$ bition of colon activity. Gastroenterology 1986; 90: 400-7.

22 Gillespie JG, Khoyi MA. The site and receptors responsible $\delta$ for the inhibition by sympathetic nerves of intestinal Physiol (Lond) 1977; 267: 767-89.

23 Ek B, Lundgren B. Characterization of the beta adrenergic inhibition of motility in cat colon strips. Eur $\mathcal{F}$ Pharmacol 1982; 77: 25-31.

24 Ek BA, Nahorski SR. $\beta$-Adrenergic control of motility in the rat colon. II. Proportions of $\beta_{1}$ and $\beta_{2}$-adrenoceptors $N$ identified with ${ }^{125} \mathrm{I}-(-)$ pindolol binding. Gastroenterology 1986; 90: 408-13.

25 Jacob H, Brandt LJ, Farkas P, Frishman W. Beta-adrenergic O blockade and the gastrointestinal system. Am $\mathcal{F}$ Med 1983; $\mathrm{\omega}$

26 Leroch Z, Wegreyn T, Zieba D, Gutowski S, Debowy J. Analysis of the role of adrenergic receptors in the regulation of small intestine motor activity in sheep. Acta regulation of smal intestine motor activity in sheep. Acta $\mathbb{D}$

27 Greenwood B, Tremblay L, Davidson JS. Sympathetic control of motility, fluid transport, and transmural $T_{T}$ potential difference in the rabbit ileum. Am $\mathcal{F}$ Physiol $\bar{O}$ 1987; 253: G726-9.

28 Greenwood B, Davidson JS, Dodds WJ. Influence of $\subseteq$ selective $\alpha$-and $\beta$-adrenoceptor antagonists in the control $\mathbb{D}$ of the motor activity and transmural potential in the rabbit $\varrho$ ileum in vitro. Foumal of Gastrointestinal Motility 1990; $2: \sigma$ 47-52.

29 Norman BJ, Leathard HL. Evidence that an atypical $\varnothing$ $\beta$-adrenoceptor mediates the inhibition of spontaneous induced by ritodrine and salbutamol. $\mathrm{Br} \mathcal{f}$ Pharmacol $\overline{\mathrm{Q}}$ induced by ritodrin

30 Vliet A van der, Rademaker B, Bast A. A beta adrenoceptor with atypical characteristics is involved in the relaxation of the rat small intestine. $\mathcal{F}$ Pharmacol Exp Ther 1990; 255: 218-26.

31 Morris AI, Turnberg LA. Influence of isoproterenol and propranolol on human intestinal transport in vivo. Gastroenterology 1981; 81: 1076-9.

32 Valori RM, Kumar D, Wingate DL. Effects of different types of stress and of "prokinetic" drugs on the control of the fasting motor complex in humans. Gastroenterology 1986; 90: 1890-900. 